\title{
Use of a scoring technique to assess the effect of field variability on yield of pearl millet grown on three Alfisols in Niger. \\ M. GANDAH ${ }^{1 *}$, J. BOUMA $^{2}$, J. BROUWER ${ }^{3}$ AND N. VAN DUIVENBOODEN ${ }^{4}$
}

1. INRAN, B.P. 429, Niamey, Niger, * corresponding author

2. Dept. of Soil Science and Geology, Wageningen Agricultural University, PO Box 37, NL-6700 AA Wageningen, The Netherlands

3. Dept. of Agronomy Wageningen Agricultural University, PO Box 341, NL-6700 AH Wageningen, The Netherlands

4. ICRISAT, B.P. 12404, Niamey, Niger

* Corresponding author (fax: +227 7221 44; e-mail: g.mahamadou@cgnet.com)

Received 28 May 1997; accepted 15 March 1998

\begin{abstract}
Within-field spatial variability of pearl millet was studied at three different sites on Alfisols in Niger. Grain yields in fields on a North-South gradient were 8-383, 2-1343, 7-815 $\mathrm{kg} \mathrm{ha}^{-1}$, with a coefficient of variation of 61, 55, and $53 \%$, respectively. Variability was explained by soil chemical factors for only 5 to $28 \%$. A simple method of scoring millet growth of individual hills a few weeks before harvest was tested for measuring yield variability in a field as an alternative for expensive soil chemical analyses. The median score value explained 25,67 , and $8 \%$ of the variability for the same gradient. As a verification step, map pattern comparisons of millet grain and straw yields with median score values gave low taxonomic distances (0.01-1.7), indicating significant similarities in variability. The hill scoring method is an appropriate tool to identify millet grain and straw yield variability.
\end{abstract}

\section{Résumé}

La variabilité spatiale du mil au niveau du champ a été étudiée sur trois sites différents d'Alfisols au Niger. Les rendements en grains dans les champs sur un gradient nord-sud ont été de 8-383, 2-1343 and 7-815 $\mathrm{kg} \mathrm{ha}^{-1}$, avec un coefficient de variation de 61,55 , et $53 \%$, respectivement. Les facteurs de propriétés chimiques du sol expliquent seulement 5 à $28 \%$ de cette variabilité. Une méthode simple de notation de la croissance du mil à partir de poquets individuels quelques semaines avant la récolte a été testée pour mesurer la variabilité de rendement dans un champ. Cette méthode a été testée comme alternative aux analyses de sol qui sont très coûteuses. Sur le même gradient, la médiane du score pouvait expliquer 25,67 , et $8 \%$ de la variabilité. Une comparaison des cartes de rendements en grains et paille avec la carte de score médian a montré des distances taxonomiques faibles (0.01-1.7), signes d'une grande similarité dans la variabilité. Les résultats montrent que l'utilisation de la notation de la croissance des poquets de mil peut être un bon indicateur pour identifier la variabilité du rendement en grains et paille.

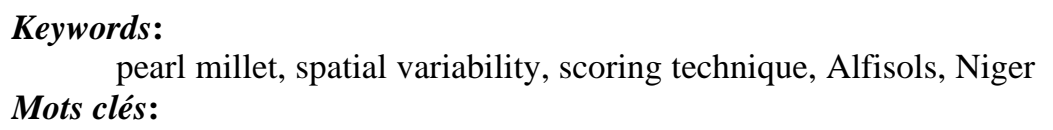

variabilité spatiale, mil, technique de notation

\section{Introduction}

Spatial variability of crop growth within fields is a prominent feature in the Sudano-Sahelian zone of West Africa. Soil physical differences and highly variable soil fertility patterns within fields are not homogenized by chemical fertilization or tillage to the same extent as in more mechanized and capitalized types of agriculture in the developed world. Brouwer et al. (1993) concluded that in traditional land use systems, where high risks are 
involved in crop production, field variability may be an asset in avoiding complete crop failure. They hypothesized that water was more limiting in higher and drier areas of the field in years of low rainfall and nutrients more limiting in lower and more leached areas when rainfall was high. This variability poses problems in agronomic experiments, and cannot be fully explained on the basis of available data (Wendt, 1986; Wendt et al., 1993; Buerkert et al., 1995). Variability is often observed in patterns of soil and plant characteristics. The patterns may occur in single or interrelated patches in the field. Relations between different management practices and yields are difficult to document because the implicit statistical assumption that conditions within treatment blocks are homogeneous is not met. Management measures are, however, applied uniformly over a field and occurrence of internal variability implies that the effect of such measures is bound to be reduced as different spots require different treatment. The observed variability can form the basis for site-specific management in which management is varied over the field, but this requires much additional information and technology (Bouma et al., 1996). These are generally not available in West Africa partly because the means required to document spatial variability can not be incorporated in research projects.

Therefore, a research has started to develop a methodology on how to use efficiently this within-field variability in a crop production system with limited resources. The objectives of this study are to document spatial variability, to explain it on the basis of different parameters, and to test an alternative hill scoring technique in estimating yield variability within a field.

\section{Materials and methods}

At three research stations in western Niger on Alfisols (sandy soils with a slight increase in clay content from 3 to 7\% with depth), four fields were planted with pearl millet (Pennisetum glaucum L.) during the rainy season of 1995. The sites at Ouallam, Sadoré, and Tara, are located along a North- South axis, i.e. normally with an increasing rainfall gradient.

At each site, the local millet variety was planted at a density of $1 \times 1 \mathrm{~m}$ (i.e. 10,000 hills ha $^{-1}$ ). In accordance with local practices, no fertilizer or organic matter was applied nor was any land preparation carried out but the removal of shrubs and old millet plants from the 1994 crop season. At Tara, although farmers traditionally plow their land, no plowing was done to allow comparison with the other sites. Weeding of the fields was done with a hand hoe, and millet was thinned to three plants per hill during the first weeding. Within each field, with sizes of 2275 and $2700 \mathrm{~m}^{2}$ (Ouallam), $6750 \mathrm{~m}^{2}$ (Sadoré) and $2125 \mathrm{~m}^{2}$ (Tara), $5 \times 5 \mathrm{~m}$ plots were laid out without alleys (Figure 1). At Ouallam, millet was planted on June 25. Hill scoring was done at 85 days after sowing (DAS), and the crop was manually harvested at 115 DAS. For Sadoré, the dates were, June 20, 67 DAS, and 115 DAS, and for Tara, June 17, 75 DAS and 110 DAS. Dry weight of all plant components per plot were obtained after air-drying for 2-3 weeks, and samples were oven-dried for moisture correction. Other observations included the number of hills and heads harvested, daily rainfall and the location of old shrubs, termites and ants mounds, and flooded areas.

Soil samples were taken after harvest in a $10 \times 10 \mathrm{~m}$ grid at grid points, and additionally in each of the four $5 \times 5$ $\mathrm{m}$ plots surrounding a grid point in 5 selected locations (Figure 1). This implied for Sadoré 20 soil samples and corresponding yields from the sampled plots, and 63 soil samples at grid points, each having the average yield from the four surrounding plots. Soil samples were taken at 0-10, 10-20, and 20-40 cm depth for three reasons. Firstly, 80 to $90 \%$ of millet roots occur in the $0-40 \mathrm{~cm}$ layer which explains most of the soil chemical effects on millet yield. Secondly, most of the changes in soil nutrients occur in this 0-40 cm layer (A. Bationo, pers. comm. 1997) or even in the 0-20 cm layer (Geiger et al., 1992). Finally, the amounts of nitrogen under the given conditions at larger depth are rather insignificant. Soil samples were analyzed for $\mathrm{pH}-\mathrm{H}_{2} \mathrm{O}, \mathrm{ECEC}(\mathrm{Ca}, \mathrm{Mg}, \mathrm{Na}, \mathrm{K}, \mathrm{Al}$, and $\mathrm{H}), \mathrm{P}_{\mathrm{Bray}}$, C, and texture (Van Reeuwijk, 1993). Soil and plant data were analyzed with SPSS-6.01 (Anonymous, 1988) and Surfer (Anonymous, 1995).

A topographic survey of each field was made after harvest. A level was used, and an elevation reading was taken at the corners of the plots. A topographic map was made for each site from these measurements.

\section{Hill scoring technique}

The hill scoring technique measures variability in crop growth within a field at a certain moment in time. The technique, developed by Buerkert et al. (1995), scores the development stage of the plant in a hill which reflects the reaction of the plant to its environment (soil, weather, pests, and human action). In a non-fertilized, uniformlyplanted and maintained field, crop growth is affected by soil and weather, the latter being considered uniform in fields of the size used in the experiment (c.f. Sivakumar \& Hatfield, 1990). Hence, growth can be related in such a field to soil physical, chemical, and topographic characteristics. 
The scoring is done in three steps (Buerkert et al., 1995):

a. touring the field to get a general appreciation of hill development,

b. setting a scale of hill vigor with maximally nine classes, and

c. the actual scoring of rows.

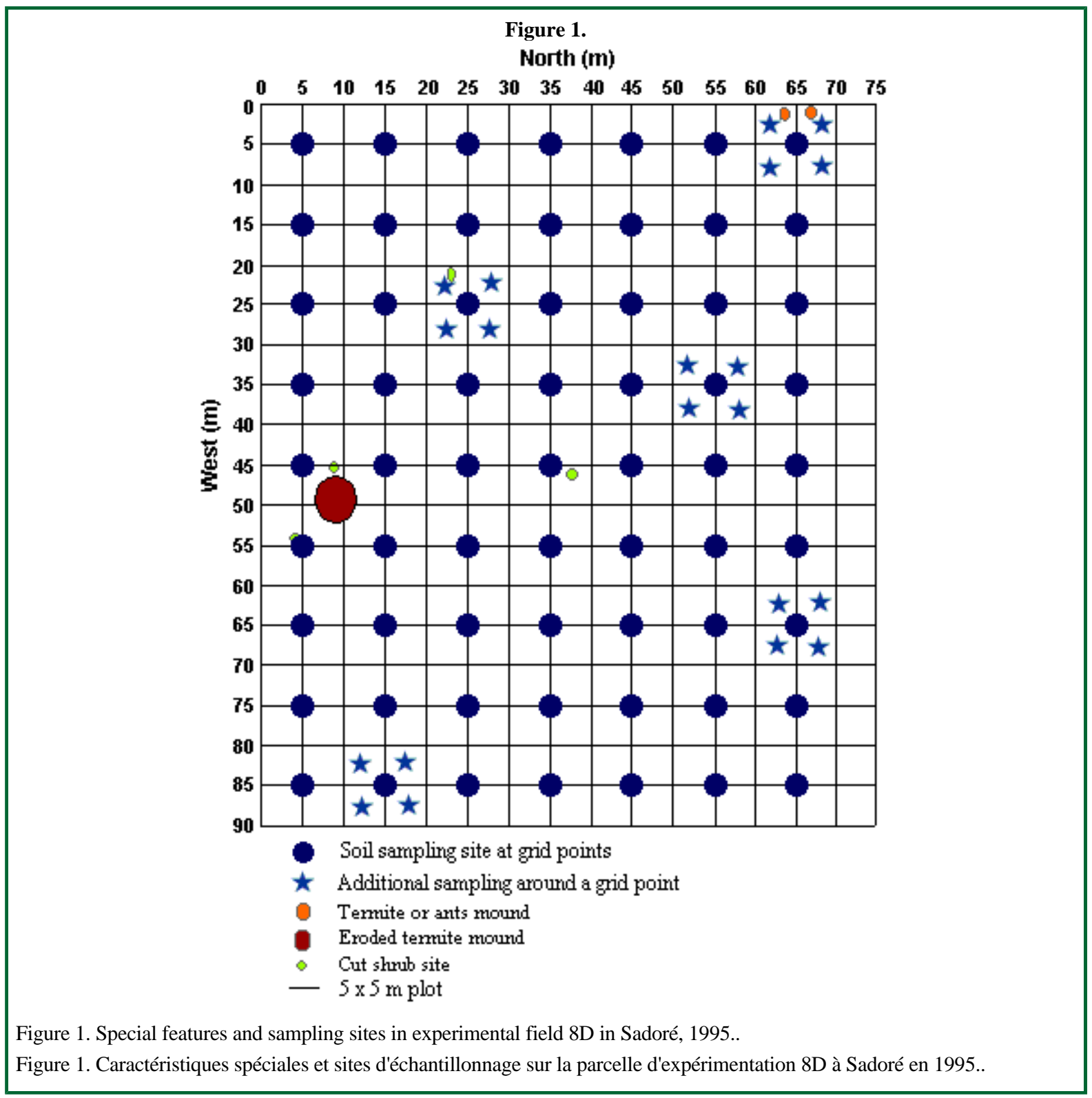

In this study, the technique was adapted in two ways: the scale ranged from 0 (no plant present) to 8 (best development), and individual hills were scored to allow geo-statistical analysis (coordinates: $\mathrm{x}, \mathrm{y}$, and $\mathrm{z}$ : the score).

\section{Spatial variability analysis}

Spatial variability is analyzed in two ways. Firstly, a global analysis of geo-referenced data is conducted using means and coefficients of variations $(\mathrm{CV})$, followed by stepwise regression to relate yield with measured soil and plant factors.

Secondly, a map pattern comparison (MPC) technique is used (Davis, 1986). This technique was adapted; block kriging (Stein et al., 1997) and a pattern analysis based on Van Uffelen et al. (1997) were performed to compare quantitatively the three maps (yield, straw, and median hill score) created with Surfer (Ver. 6.01). The patterns in the maps were compared and expressed as the taxonomic distance $(d)$, low value indicating similarity, and a high values a large difference. To obtain that value, various steps are required using geo-statistical packages (Deutsch \& Journel, 1992; Heuvelink, 1993) and routines written in Interactive Data Language (IDL, Ver. 3.61a). The ranges of the two maps may be considerably different, the standard normal value $(Z)$ of the factors is used at the nodes of a 
grid mesh. $Z$ is calculated as:

$$
z_{n, x y}=\frac{v_{n, x y}-\bar{v}_{n}}{S_{n}}
$$

where, $=$ measured value; $=$ the average of $; S_{n}=$ standard deviations of $\quad$ in the pattern $n$.

The comparison of patterns can only be done for a sample area of a limited size or window with identical positions in the two maps. After making the comparison, the window is subsequently moved to a new lateral position while keeping $80 \%$ of the area in the former windows and adding $20 \%$ new area in the case of a $5 \times 5 \mathrm{~m}$ window. For each window, a polynomial regression is fitted to obtain a $Z$ for the window. This is calculated by:

$$
\begin{aligned}
z_{\text {win } x y}= & b_{n, 0}+b_{n, 1} * x_{\text {win }}+b_{n, 2} * y_{\text {win }}+b_{n, 3} * x^{2}{ }_{\text {win }}+b_{n, 4} * y^{2}{ }_{\text {win }}+ \\
& b_{n, 5} * x y_{\text {win }}+b_{n, 6} * x_{\text {win }}^{3}+b_{n, 7} * y_{\text {win }}^{3}+b_{n, 8} * x^{2} y_{\text {win }}+b_{n, 9} * x y^{2} \text { win }
\end{aligned}
$$

where, $b_{n, 0-9}=$ regression coefficients obtained by the least square regression method of pattern $\mathrm{n}$ in the window; $\mathrm{x}$ and $\mathrm{y}=$ coordinates.

The taxonomic distance $(d)$, can now be calculated on the basis of the regression coefficients from Equation $\underline{2}$ :

$$
d=\sqrt{\sum_{i=0}^{p-1} \frac{\left(b_{1, i}-b_{2, i}\right)^{2}}{p}}
$$

where, $b_{1, i}=$ regression coefficients for map $1 ; b_{2, i}=$ regression coefficients for map $2 ; \mathrm{p}=$ level of polynomial regression.

Since the size of the window has an influence on the effect of the coefficients in Equation 2 , a weight is applied to $d$, so that Equation $\underline{3}$ becomes:

$$
d_{W}=\sqrt{\sum_{i=0}^{p-1} \frac{\left(w_{i}\left(b_{1, i}-b_{2, i}\right)^{2}\right)}{\sum_{i=0}^{p-1} w_{i}}}
$$

where, $\mathrm{w}=$ weight applied equal to the range along the $\mathrm{z}$-axis for the polynomial term $i$ and function of window size and mesh distance.

The calculated $d_{w}$ values and the coordinates of the center of the windows are used to obtain the taxonomic distance maps. Two types of taxonomic maps are made: median score-grain yield $\left(d_{w m g}\right)$, and median score-straw yield $\left(d_{w m s}\right)$. No method for setting a threshold level of $d$ was found in the literature. A $d_{w}$ value of zero for two windows means identical pattern, but there is no set value for opposite patterns. It is proposed here to use the median $d_{w}$ as a threshold value of each map to identify patterns with high dissimilarity shown in light gray representing $d_{w}$ values higher than median.

\section{Results and discussion}

In 1995, total rainfall was $100 \mathrm{~mm}$ above average at Ouallam and Sadoré. The Tara site showed a severe deficit with about $350 \mathrm{~mm}$ less than the ten years average (Table 1), in analyzing rainfall data, the number of rainy days is a factor, implying the best rainfall distribution in Tara.

Table 1. Rainfall characteristics at the three research sites in Niger.

Tableau 1. Caractéristiques de la pluviométrie sur les trois sites de recherche au Niger.

\begin{tabular}{|l|c|c|c|c|}
\hline \multicolumn{1}{|c|}{ Site } & $\begin{array}{c}\text { Average } \\
1985-1994\end{array}$ & Total rainfall in 1995 & $\begin{array}{c}\text { Useful rain in 1995 } \\
\text { (planting to harvest) }\end{array}$ & No of rainy days \\
\hline Ouallam & 468.8 & 574.4 & 546.2 & 27 \\
\hline Sadoré & 563.3 & 663.7 & 557.2 & 32 \\
\hline Tara & 818.9 & 469.3 & 417.5 & 40 \\
\hline
\end{tabular}

*) Rainfall $>0.8 \mathrm{~mm}$ 
The Alfisols at all three sites are classified as coarse kaolinitic Psammentic Ustalfs (Anonymous, 1994). At Ouallam and Sadoré, they are Psammentic Paleustalfs (West et al., 1984) with a profile deeper than 6 meters. At Tara, the soil depth is shallower. The sandy soils differ in physical and chemical characteristics (Table 2), but all are slightly acidic and are very low in carbon, phosphorus, and a low effective cation exchange capacity.

\begin{tabular}{|c|c|c|c|c|c|}
\hline & & \multicolumn{2}{|c|}{ Ouallam } & \multirow[t]{2}{*}{ Sadoré } & \multirow[t]{2}{*}{ Tara } \\
\hline & & Field 1 & Field $2 *$ & & \\
\hline \multicolumn{2}{|l|}{$\mathrm{pH}-\mathrm{H}_{2} \mathrm{O}$} & 5.6 & 5.2 & 5.9 & 5.6 \\
\hline \multirow[t]{3}{*}{ Texture } & -Sand (\%) & 93.0 & 92.2 & 89.8 & 82.0 \\
\hline & -Silt (\%) & 3.2 & 3.7 & 4.5 & 14.2 \\
\hline & -Clay (\%) & 3.8 & 4.1 & 5.7 & 3.8 \\
\hline \multicolumn{2}{|c|}{ Carbon (\%) } & 0.14 & 0.10 & 0.20 & 0.25 \\
\hline \multicolumn{2}{|c|}{$\mathrm{P}\left(\mu \mathrm{g} \mathrm{g}^{-1}\right)$} & 0.8 & $3.8^{*}$ & 4.0 & 0.22 \\
\hline \multicolumn{2}{|c|}{$\mathrm{K}$ (meq. $100 \mathrm{~g}^{-1}$ ) } & 0.04 & 0.50 & 0.10 & 0.08 \\
\hline \multicolumn{2}{|c|}{ ECEC (meq. $100 \mathrm{~g}^{-1}$ ) } & 0.73 & 0.70 & 0.81 & 1.00 \\
\hline \multicolumn{2}{|c|}{ Number of plots } & 91 & 108 & 270 & 85 \\
\hline
\end{tabular}

* Field used previously for millet seed production and left under fallow for 3 years.

Grain production within each field was highly variable as indicated by high coefficients of variation above $50 \%$ at all sites (Table 3). For straw, the CV is in the same order of magnitude.

\begin{tabular}{|c|c|c|c|c|c|}
\hline \multirow[b]{2}{*}{ Factors } & \multirow[t]{2}{*}{ Sites } & \multicolumn{2}{|c|}{ Ouallam } & \multirow[t]{2}{*}{ Sadoré } & \multirow[t]{2}{*}{ Tara } \\
\hline & & Field 1 & Field 2 & & \\
\hline \multirow[t]{5}{*}{ Grain } & mean & 110 & 125 & 379 & 332 \\
\hline & SD & 65 & 80 & 208 & 177 \\
\hline & CV (\%) & 59 & 64 & 55 & 53 \\
\hline & Min. & 8 & 13 & 2 & 7 \\
\hline & Max. & 313 & 383 & 1343 & 815 \\
\hline \multirow[t]{5}{*}{ Straw } & mean & 915 & 602 & 1097 & 744 \\
\hline & SD & 642 & 396 & 654 & 358 \\
\hline & CV $(\%)$ & 70 & 66 & 60 & 48 \\
\hline & Min. & 80 & 80 & 74 & 104 \\
\hline & Max. & 2800 & 2000 & 4440 & 1900 \\
\hline \multirow[t]{5}{*}{ TDM } & mean & 1025 & 726 & 1709 & 1319 \\
\hline & SD & 680 & 462 & 956 & 580 \\
\hline & CV (\%) & 66 & 63 & 56 & 44 \\
\hline & Min. & 104 & 96 & 80 & 254 \\
\hline & Max. & 2927 & 2333 & 6080 & 2920 \\
\hline \multirow[t]{5}{*}{ HI } & mean & 0.12 & 0.16 & 0.22 & 0.26 \\
\hline & SD & 0.05 & 0.05 & 0.04 & 0.19 \\
\hline & CV $(\%)$ & 41 & 31 & 18 & 73 \\
\hline & Min. & 0.02 & 0.06 & 0.02 & 0.03 \\
\hline & Max. & 0.30 & 0.30 & 0.32 & 0.55 \\
\hline \multicolumn{2}{|c|}{ Number of plots } & 91 & 108 & 270 & 85 \\
\hline
\end{tabular}

TDM: total dry matter HI: harvest index

The regression of yield on the most important soil factors showed only weak association (Table 4). Moreover, they were different for each site. At Ouallam, similar to Tara, soil factors explained 5 to $13 \%$ of yield variability, whereas at Sadoré, this was somewhat higher. This confirms that soil chemical properties do not properly explain 
grain yields in this type of agricultural production systems where the content of key elements is below the minimum level required for a good millet crop (Stein et al., 1997). The variability is further influenced by bare spots (erosion crusts or old termite mounds) and micro-topographical differences affecting water redistribution and consequently grain yield (Gaze, 1996). The rainfall concentration factor (i.e. infiltration/rainfall), ranging from 0.3 to 3.4 in Gaze's experiments, had a considerable influence on yields in semi-arid conditions as it modified micro-site water and probably nutrient balances. Crop weeding operations did not mix the top soil layer deeply enough to eliminate this micro-relief as it was still present at the end of the cropping season.

Table 4. Linear regression models of millet grain yield $\left(\mathrm{kg} \mathrm{ha}^{-1}\right)$ with soil and plant factors measured at the three sites in Niger in 1995 .

Tableau 4. Modèles de régression linéaire du rendement grain de mil $\left(\mathrm{kg} \mathrm{ha}^{-1}\right)$ avec des facteurs sol et plante mesuré sur les trois sites au Niger en 1995.

\begin{tabular}{|c|c|c|c|c|}
\hline \multirow[t]{2}{*}{ Factors in model } & \multicolumn{2}{|c|}{ Ouallam } & \multirow[t]{2}{*}{ Sadoré } & \multirow[t]{2}{*}{ Tara } \\
\hline & Field 1 & Field 2 & & \\
\hline \multirow[t]{2}{*}{ Soil } & $802.5 \mathrm{Mg}+39.6$ & $\begin{array}{l}524.3 \mathrm{C}- \\
178.4 \mathrm{ECEC} \\
+186.1\end{array}$ & $\begin{array}{l}384 \mathrm{Ca}-805.9 \mathrm{Al}- \\
64.5 \mathrm{PH}+683.4\end{array}$ & $952.7-110.1 \mathrm{PH}$ \\
\hline & $r^{2}=0.06$ & $r^{2}=0.13$ & $r^{2}=0.28$ & $r^{2}=0.05$ \\
\hline \multirow[t]{2}{*}{ Plant } & $0.62 S+58.3$ & $0.16 S+27.8$ & $0.29 S+62.6$ & $0.28 \mathrm{~S}+121.3$ \\
\hline & $r^{2}=0.25$ & $r^{2}=0.64$ & $\mathrm{r}^{2}=0.81$ & $\mathrm{r}^{2}=0.32$ \\
\hline \multirow[t]{2}{*}{ Score } & 24.7MED - 10.3 & 25.8MED - 12.4 & 133.9MED -16 & 37.2MED +236.9 \\
\hline & $\mathrm{r}^{2}=0.24$ & $r^{2}=0.26$ & $r^{2}=67$ & $\mathrm{r}^{2}=0.08$ \\
\hline \multirow[t]{2}{*}{ Soil and plant } & $\begin{array}{l}3330 \mathrm{Na}+0.08 \mathrm{~S}- \\
0.22\end{array}$ & $\begin{array}{l}1967.7 \mathrm{Na}+0.16 \mathrm{~S} \\
+4.41\end{array}$ & $\begin{array}{l}981.4 \mathrm{H}-569.2 \mathrm{Al} \\
+0.27 \mathrm{~S}+60\end{array}$ & $\begin{array}{l}402.9 \mathrm{P}-327.7 \mathrm{Mg} \\
+0.3 \mathrm{~S}+75.2\end{array}$ \\
\hline & $r^{2}=0.35$ & $r^{2}=0.65$ & $\mathrm{r}^{2}=0.83$ & $\mathrm{r}^{2}=0.49$ \\
\hline \multirow[t]{2}{*}{ Soil +plant +score } & $\begin{array}{l}3106 \mathrm{Na}+0.06 \mathrm{~S} \\
+12.4 \mathrm{MED}\end{array}$ & $\begin{array}{l}806.3 \mathrm{Na}+0.12 \mathrm{~S} \\
+9.32 \mathrm{MED}-18.65\end{array}$ & $\begin{array}{l}838.9 \mathrm{H} \\
+36.7 \mathrm{MED} \\
+0.21 \mathrm{~S}-505 \mathrm{Al} \\
+19.9\end{array}$ & $\begin{array}{l}0.3 \mathrm{~S}-327.7 \mathrm{Mg}+ \\
402.9 \mathrm{P}+75\end{array}$ \\
\hline & $\mathrm{r}^{2}=0.38$ & $r^{2}=0.55$ & $\mathrm{r}^{2}=0.85$ & $r^{2}=0.41$ \\
\hline
\end{tabular}

ECEC=effective cation exchange capacity ; $\mathrm{Ca}=$ calcium; $\mathrm{Al}=$ aluminum; $\mathrm{Mg}=$ magnesium; $\mathrm{Na}=$ sodium; $\mathrm{H}=$ hydrogen; meq. 100g-1 P=phosphorus in $\mu \mathrm{g} \mathrm{g}^{-1} ; \mathrm{PH}=\mathrm{pH} ; \mathrm{C}=$ carbon in \%; $\mathrm{S}=$ straw yield $\left(\mathrm{kg} \mathrm{ha}^{-1}\right) ; \mathrm{MED}=$ median score;

When straw yield was correlated with grain yield, only two out of the four fields studied had an acceptable fit, with the best relationship at Sadoré. When the number of millet heads and hills at harvest are also included in the regression model for this site, $\mathrm{r}^{2}$ increases to $90 \%$ (not shown). Major disadvantages of this regression method, such as straw yield being only available after harvest and the requirement of an oven, makes it unfit for an a-priori yield estimation. Moreover, a severe lack of fit could be obtained when damage to millet ears (from ear worm, birds, etc.) occurs just before harvest.

\section{Hill scoring technique}

Plant scoring at the three sites showed a normal population of hill scores with mean almost equal to the median (Table $\underline{5}$ ).

Table 5. Descriptive statistics of millet hill scores at the three sites in Niger in 1995.

Tableau 5. Statistique descriptive des scores de poquets de mil sur trois sites au Niger en 1995.

\begin{tabular}{|l|c|c|c|c|}
\hline Statistics & \multicolumn{2}{|c|}{ Ouallam } & Sadoré & \\
\cline { 2 - 5 } & Field 1 & Field 2 & \\
\hline Mean & 4.63 & 4.97 & 2.93 & 2.63 \\
\hline Stand. Error & 0.05 & 0.04 & 0.02 & 3 \\
\hline Median & 5 & 5 & 3 & 2.26 \\
\hline SD & 2.05 & 2.02 & 1.78 \\
\hline CV $(\%)$ & 44 & 40 & 61 & 86 \\
\hline
\end{tabular}

Having obtained the same standard error of the mean and about the same CV at the two fields in Ouallam, this confirms the uniform variability found in the previous analysis. The mean value of 5 should not be used in a 
straight-forward comparison with the other two sites since, the scoring scales used here were shifted down due to poor growth. For all three sites, the $\mathrm{CV}$ is between 44 and $86 \%$ indicating a high variability in hill growth. Hill scoring gives also the variability in the number of successful hills in the field. At Sadoré, for instance, the average number of cropped hills in the 270 plots was $8,888 \mathrm{ha}^{-1}$ (i.e. $89 \%$ of planted hills) with a range of 3,600 to 10,000 hills $\mathrm{ha}^{-1}$. At Ouallam and Tara, the average was 93\%. These average values exceed the threshold value of 6,000 hills $\mathrm{ha}^{-1}$ above which fertilizer input can produce an optimum return (Bationo et al., 1992), indicating that there is room for improvement in management.

The regression analysis of median score with grain yield (Table 4 ), although with lower $\mathrm{r}^{2}$ values than with straw yield, presented an improvement when compared with those with soil parameters.

\section{Spatial variability analyses}

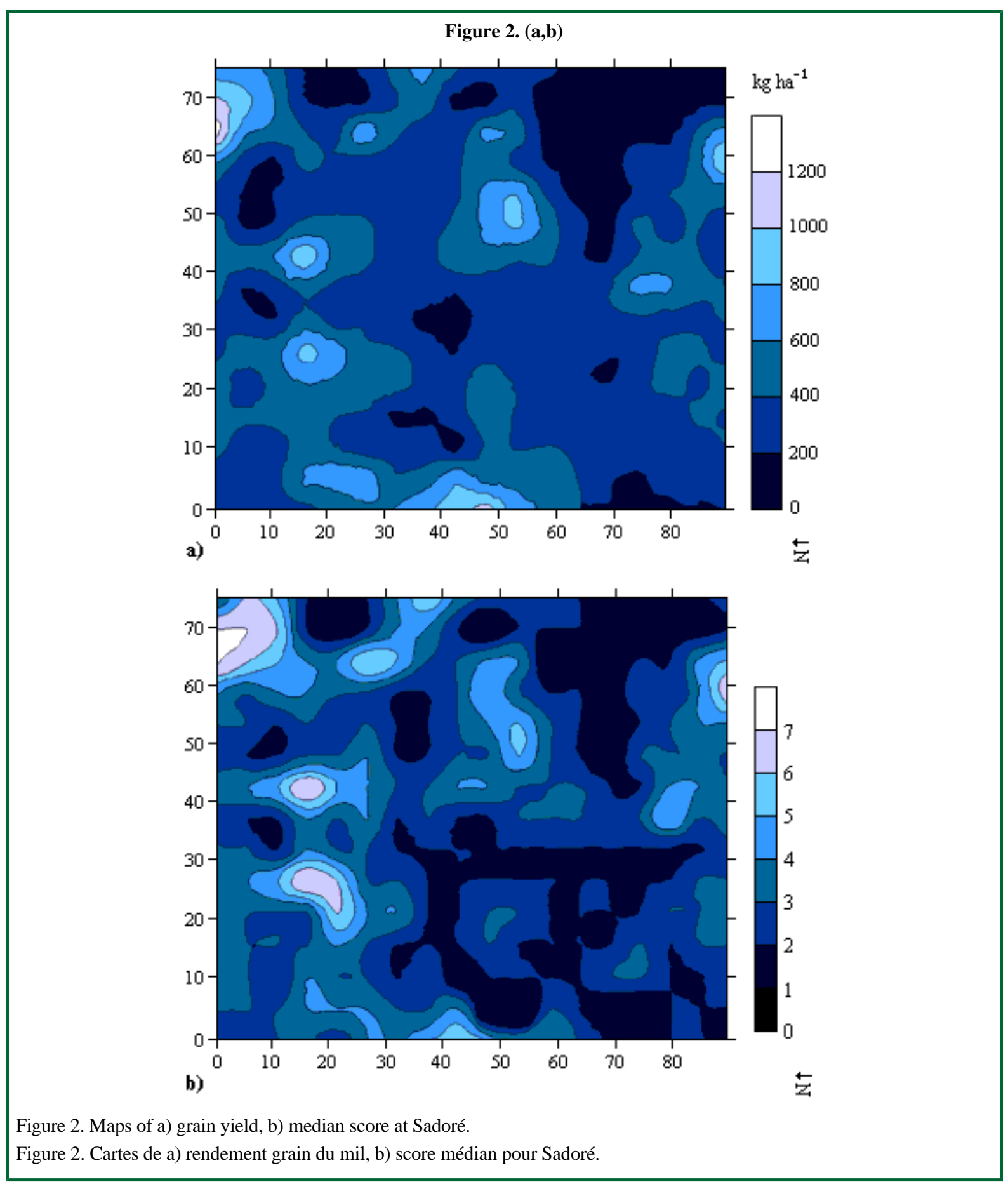

The MPC technique comparing score and grain yield resulted at Ouallam in higher $d_{w m g}$ values for field 1 than field 2 (Table $\underline{6}$ ), most likely being explained by a more uniform micro-topography in field 2 . Within each of the two fields there, the range of $d_{w m g}$ and $d_{w m s}$ was about the same, while at Sadore they were identical. Figures 2c (map of $d_{w m g}$ ) and $2 \mathrm{~d}$ (map of $d_{w m s}$ ) show the dissimilarity between the scoring and biomass production indicated in light 
shading. This dissimilarity has been quantified also for the other sites (Table $\underline{6}$ ) showing that Sadoré has the lowest value. Using Figure 1 , it can be derived that the mismatch occurs in spots with an eroded termite mound, a cut down shrub site, an active termite mound and a low area with water run-on. At Ouallam, the dissimilarity is caused by medium size shrubs in the field. At Tara, the equal percentage of field with dissimilarity for straw and grain yields can be explained by the recently cleared nature of the field.

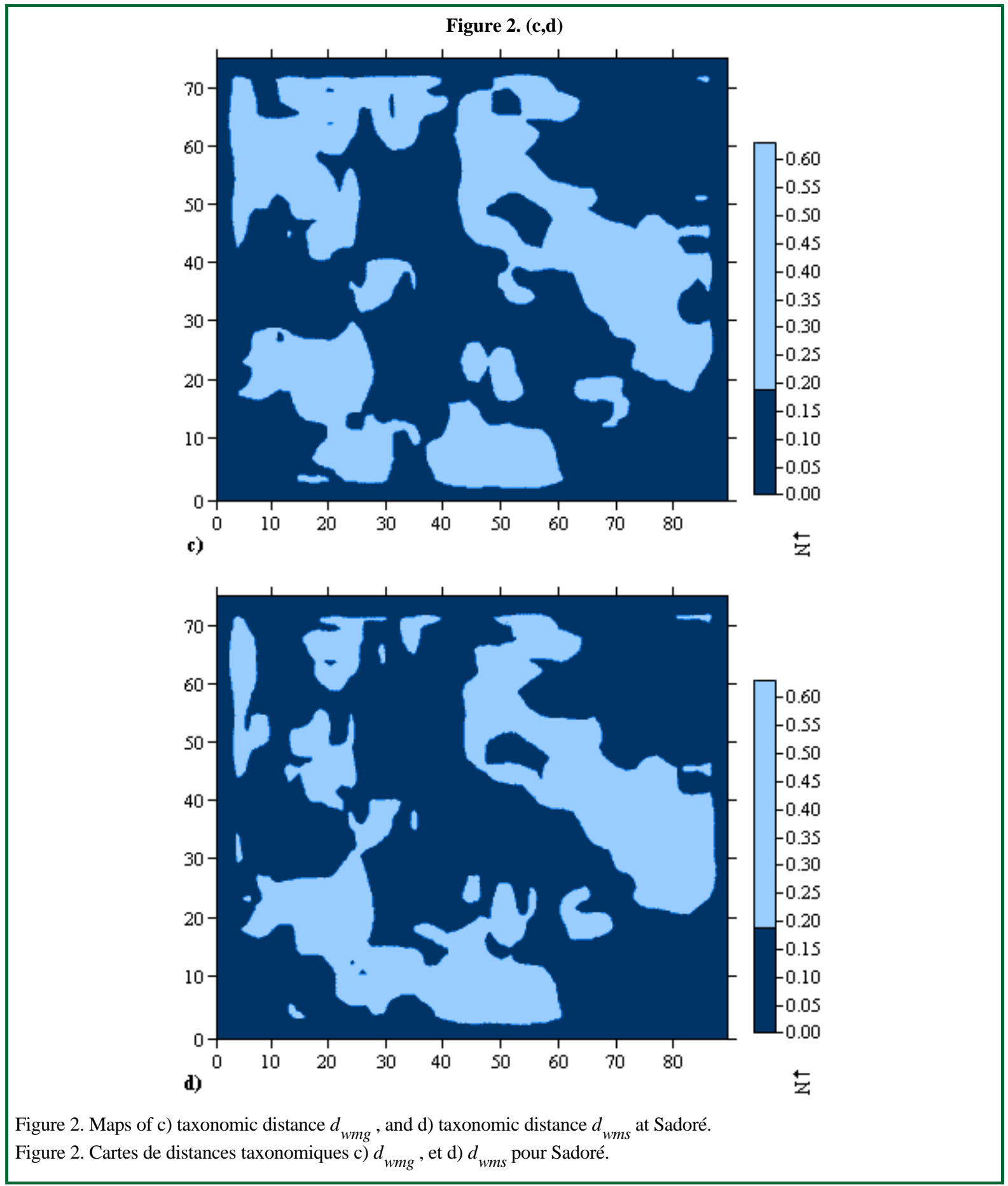

These spots with high $d$ can then be further investigated to identify their occurrence at the same location with time. The method whereby scoring was carried out at about 45 days before harvest need to be validated. In a follow up study, scoring was done three times during the growing season to establish the best period.

\section{Conclusions}

The hill scoring technique gives an insight in the within-field variability which is further quantified through the MPC technique. The latter confirms largely the variability obtained by the former, so that the hill scoring technique can be considered as a relatively good estimation method. From this study on variability of millet yields it is concluded that, at all the three sites in western Niger, variability was large within a site, and also between the sites. 
The soil physical and chemical characteristics taken individually do not explain adequately the observed yield differences by a common linear regression analysis.

The use of hill scoring method proved to be cheap way to measure growth variability in fields. Median scores correlated with millet yields were better than with soil factors when done at millet heading stage (about 45 days before harvest) in 1995. The technique can be used to quantify field variability and may help to design site specific soil management schemes at low costs, but further testing is required before recommendations for farmers can be designed.

Table 6. Characteristics of comparing scoring and plant components at the three sites in Niger.

Tableau 6. Caractéristiques de la comparaison du score et des facteurs plante sur les trois sites au Niger.

\begin{tabular}{|c|c|c|c|c|c|}
\hline & \multicolumn{2}{|c|}{ Ouallam } & \multirow[t]{3}{*}{ Sadoré } & \multirow[t]{3}{*}{ Tara } \\
\hline & & Field 1 & Field 2 & & \\
\hline \multicolumn{4}{|c|}{ Range } & & \\
\hline$d_{w m g}$ & Min & 0.12 & 0.02 & 0.03 & 0.01 \\
\hline \multirow[t]{3}{*}{$d_{w m s}$} & Max & 1.72 & 0.70 & 0.64 & 1.12 \\
\hline & Min & 0.11 & 0.03 & 0.03 & 0.04 \\
\hline & Max & 1.76 & 0.71 & 0.63 & 1.12 \\
\hline \multicolumn{6}{|c|}{$\begin{array}{l}\text { Maps compared (in } \% \text { of field } \\
\text { area with high pattern } \\
\text { dissimilarity) }\end{array}$} \\
\hline \multicolumn{2}{|c|}{ Grain yield and median score } & 43 & 46 & 35 & 43.6 \\
\hline \multicolumn{2}{|c|}{ Straw yield and median score } & 42 & 59 & 36 & 43.5 \\
\hline
\end{tabular}

\section{References}

Anonymous, 1995.

User guide Surfer Ver 6.01.

Golden Software Inc. Colorado, 600 pp.

\section{Anonymous, 1994.}

Keys to Soil Taxonomy.

United States Department of Agriculture. Soil Conservation Service. Sixth edition. United States of

America, 524 pp.

Anonymous, 1988.

SPSS/PC+ V2.0 Base manual.

SPSS Inc., Chicago, 215 pp.

Bationo, A., C.B. Christiansen, W.E. Baethgen \& A.U. Mokwunye, 1992.

A farm level evaluation of nitrogen and phosphorus fertilizer use and planting density for pearl millet production in Niger.

Fertilizer Research 31: 175-184.

Bouma, J., J. Verhagen, J. Brouwer \& J.M. Powell, 1996.

Using systems approaches for targeting site specific management on field level.

In: M.J. Kropff, P.S. Teng, P.K. Aggerwal, J. Bouma, B.A.M. Bouman, J.W. Jones, \& H.H. Van Laar (Eds), Applications of Systems Approaches at the Field Level. Kluwer Academic Press, Dordrecht, pp. 25-36.

Brouwer, J., L.K. Fussel \& L. Herrmann, 1993.

Soil and crop growth micro-variability in the West African semi-arid tropics: a possible risk reducing factor for subsistence farmers.

Agriculture, Ecosystems and Environment 45: 229-238.

Buerkert, A., R.D. Stern \& H. Marschner, 1995.

Post stratification clarifies treatment effects on pearl millet growth in the Sahel.

Agronomy Journal 87: 752-761.

Davis, C., 1986.

Statistics and data analysis in geology.

John Wiley, New York, 550 pp. 
Deutsch, C.\& A.G. Journel, 1992.

GSLIB Geostatistical software library and user's guide.

Oxford University Press, New York, 340 pp.

Heuvelink, G.B.M., 1993.

WLSFIT manual.

University of Amsterdam, Amsterdam, 5 pp.

Gaze, S.R., 1996.

Water balance of farmer-managed millet and fallow savannah on sandy soils in South West Niger. PhD thesis.

Department of soil science, University of Reading, Reading, 268 pp.

Geiger, S.C., A. Manu \& A. Bationo, 1992.

Changes in a sandy Sahelian soil following crop residue and fertilizer additions.

Soil Science Society of America Journal 56: 172-177.

Sivakumar, M.V.K. \& J.L. Hatfield, 1990.

Spatial variability of rainfall at an experimental station in Niger, West Africa.

Theoretical applied climatology 42: 33-39.

Stein, A., J. Brouwer \& J. Bouma, 1997.

Methods for comparing spatial variability patterns of millet and soil data.

Soil Science Society of America Journal 61: 861-870.

Van Reeuwijk, L.P., 1993.

Procedures for soil analysis.

Technical Paper No. 9. International Soils Reference and Information Center, Wageningen, 100 pp.

Van Uffelen C.G.R., J. Verhagen \& J. Bouma, 1997.

Comparison of simulated crop yield patterns for site specific management.

Agricultural Systems 54: 207-222.

Wendt, J.W., 1986.

Pearl millet (Pennisetum typhoides) response to soil variability in sandy ustalfs near Niamey, Niger, West Africa. MSc thesis.

Texas A\&M University, Texas, 87 pp.

Wendt, J.W., A. Berrada, M.G. Gaoh \& G.G. Schultze, 1993.

Phosphorus sorption characteristics of productive and unproductive Niger soils.

Soil Science Society of America Journal 57: 766-773.

West L.T., L.P. Wilding, J.. Landeck, \& F.G. Calhoun, 1984.

Soil survey of ICRISAT Sahelian Center, Niger, West Africa.

Soil and Crop Science Dept. / Tropsoils. Texas A\&M University, Texas, 66 pp

\section{Acknowledgements}

The authors are thankful to Dr. W.A. Payne and his technicians for their support in the design and implementation of this study. The study was funded by the National Project for Agronomic Research in Niger (World Bank) and by the Dutch Ministry of Foreign Affairs (DGIS) funded part of ICRISAT's Desert Margins Systems Project. The manuscript was submitted as ICRISAT Journal Article 2084.

(C) NJAS 592, 1998 - Comments to: J.J.Neetson@AB.DLO.NL 